\title{
Asymmetric Suppliers' Optimal Investment Timing Decisions
}

\author{
Manoj KUMAR*
}

Received: July 2, 2018

Revised: April 8, 2019

Accepted: May 3, 2019

\begin{abstract}
This paper extends Boyle and Guthrie (2003) to investigate the interdependent effects of asymmetric financing capacities and investment costs on investment timing decisions in a duopoly with a first-mover advantage. We demonstrate several novel findings. First, suffering a significant cost disadvantage, the supplier with a larger financing capacity can still be the leader when the risk of future funding shortfalls is relatively high. Second, a weaker supplier with a significant lower financing capacity and a small cost disadvantage can even be the leader under some degree of the risk of future funding shortfalls. In addition, the weaker supplier that is still more liquidity constrained cannot be the leader anymore as its financing capacity improves and closes to that of the rival. Third, only when the risk of future funding shortfalls is relatively low, small asymmetry of investment costs can make the rival's preemption threat effective. Finally, higher project return volatility can lead to a change of the supplier's role from a follower to a leader under some degree of the risk of future funding shortfalls, thereby lowering the supplier's optimal investment trigger.
\end{abstract}

Keywords: Investment Decision, Real options; Liquidity constraints; Financing capacity; Volatility.

JEL Code Classification: G11

UDC: 336.746 .2

DOI: https://doi.org/10.17015/ejbe.2019.023.06

* SP Jain School of Global Management, Singapore. E-mail: kumarm1968@rediffmail.com

Copyright @ , 2019 Ala-Too International University. 


\section{Introduction}

The finance literature has studied well the separate effects of financing capacities and industry competition on a supplier's investment decision. Many empirical studies analyzed suppliers' investment behavior when they are subject to liquidity constraints (e.g., Almeida \& Campello, 2007; Cleary, Povel \& Raith, 2007; Denis \& Sibilkov, 2010). On the other hand, some recent empirical studies investigate suppliers' investment policies in which suppliers face some rivals strongly competing within an industry (e.g., Akdoğu \& MacKay, 2008; Akdoğu \& MacKay, 2012).

For example, Haushalter, Klasa and Maxwell (2008) provide supportive evidence that suppliers are more likely to increase investment when industry-level investment decreases if they have larger cash holdings and there is greater interdependence of their investment opportunities with rivals. Fresard (2010) recently their interrelated effects have been empirically investigated, yet they have not been analyzed in a dynamic theoretical framework. This paper manages to bridge such a gap by extending Boyle and Guthrie (2003) to investigate the interdependent effects of asymmetric financing capacities and investment costs on optimal investment timing decisions in a duopoly with the first-mover advantage.

Recently, Munos (2009) and Lyandres and Palazzo (2016) both theoretically and empirically investigate the interdependent impacts of financial constraints and competition on suppliers' optimal cash holdings decisions. Munos (2009) show that suppliers in more competitive industries hold more cash and the effects are stronger for smaller and more financially constrained suppliers. McDonald and Siegel (1986) also provide empirical evidence that competitive threats in product markets increase suppliers' cash holdings. Lyandres (2007) demonstrate that innovative suppliers' optimal cash holdings depend on competition and innovation efficacy. They also find that the proportion of cash in supplier value increases in competition but only for relatively financially constrained suppliers by using patent data. Carlson et al. (2014) also study the strategic role of cash in an industry. They find that both cash holdings and R\&D intensity increase with the winner advantage and time delay in outside financing, and decrease with entry costs.

Different from the mentioned literature, this paper focuses on the interrelated effects of financing capacity and competition on suppliers' investment decisions. Employing a leader-follower equilibrium similar to that of Carlson et al. (2014), we study the impacts of own and rival's asymmetric financing capacities on the two suppliers' roles and decisions in an investment timing game when the two suppliers are subject to asymmetric liquidity constraints and strategically compete to win a first mover advantage of an investment opportunity.

We find herein that when the risk of future funding shortfalls is relatively high, the supplier with a larger financing capacity tends to be the leader, whereas when the risk of future funding shortfalls is relatively low, the supplier with a cost advantage 
tends to be the leader. Different from the findings in real options literature that the low-cost supplier usually tends to be the leader, suffering a large cost disadvantage, the supplier with a larger financing capacity can still be the leader when the risk of future funding shortfalls is relatively high. In addition, we show that a weaker supplier with a significant lower financing capacity and a small cost disadvantage can even be the leader under some degree of the risk of future funding shortfalls. This is because when the risk of future funding shortfalls reduces the supplier with a higher financing capacity starts to enjoy the flexibility of waiting and thus delays its investment timing, and meanwhile, the risk of delaying investment of the rival supplier is still so high that its optimal investment decision is to invest as soon as possible. Accordingly, as the risk of future funding shortfalls reduces, the supplier with a small cost advantage and a greater financing capacity voluntarily defers investment and becomes the follower, while the rival supplier with a small cost disadvantage and a lower financing capacity accelerates investment and becomes the leader. We further show that the weaker supplier that is still more liquidity constrained cannot be the leader anymore when its financing capacity improves and closes to that of the rival. The reason is that as the asymmetry between the two suppliers' liquidity constraints is very small, the timings at which the two suppliers start to enjoy waiting flexibilities are so close that the weaker supplier, as usual, has no chance to be the leader.

Ever since the two seminal papers of McDonald and Siegel (1986) and Majd and Pindyck (1987) and the well-known book by Dixit and Pindyck (1994), the methodology of investment under uncertainty or real options has become the standard approach to feature a supplier's irreversible investment flexibilities. The real options literature recently pays more attention to product market competition, with some studies based on the assumption that suppliers are symmetric in Cournot-Nash oligopoly equilibrium. For example, Grenadier (2002) analyzes a supplier's delay option on an incremental investment project, and Jou and Lee (2008) focus on such an option for a lumpy investment project. With the same assumption, Aguerrevere (2009) specifically demonstrates that the relationship between the degree of competition and assets' expected rates of return varies with product market demand. Suppliers, however, are seldom identical. The growing literature on real options games suggests that, when relatively few suppliers compete, there often exists a first-mover advantage. For example, patent races are characterized by a persistent first-mover advantage, i.e., the first to invest gains an exclusive right over the technology.

The simple asymmetric duopoly equilibrium is frequently employed to analyze a supplier's irreversible investment decision when the two suppliers have different investment costs. The framework of Fudenberg and Tirole (1985) is usually employed by the real options game literature. For example, Pawlina and Kort (2006) and Mason and Weeds (2010) examine the irreversible investment behavior when there is a first-mover advantage and the competitor can potentially preempt this investment project. They generally find that the low-cost supplier will invest 
earlier due to the potential preemptive investment of the high-cost supplier when the asymmetry of investment cost is small. Recently, Carlson et al. (2014) use a similar framework to examine the effects of a supplier's expansion and contraction options on the risk dynamics of the required returns when there is a rival supplier owning the same rights.

Compared with these papers, our model contributes to the real options game literature by further taking asymmetric financing capacities between the two suppliers into consideration. We complement the literature by showing that the roles of leader and follower in an investment project are determined not only by asymmetric investment costs, but also by asymmetric financing capacities between the two suppliers. The interaction between financing capacities and industry competition is significantly important to determine the roles of the investment timing game and their optimal decisions when the threat from a rival's preemptive investment comes into play. In addition, we demonstrate that only when the risk of future funding shortfalls is low, small asymmetry of investment costs can lead to preemption. Particularly, our model offers an implication for the relationship between investment and uncertainty. In contrast to common intuition, higher investment project return volatility can lead to a change of the supplier's role from a follower to a leader, thereby lowering the supplier's optimal investment trigger. Generally, higher volatility could make a supplier's investment timing earlier, later or unchanged.

The remainder of this paper is organized as follows. Section 2 first introduces the investment environment of our model. In Section 3, we review the results of Boyle and Guthrie (2003), and then outline the optimal investment problems for the two suppliers subject to asymmetric liquidity constraints. In Section 4, we numerically investigate the roles of the investment timing game as well as the optimal decisions and provide some implications. Section 5 presents some concluding remarks.

\section{The investment environment of the model}

In this section, we first introduce the basic investment environment of our model where the two suppliers are asymmetric in both investment costs and financial capacities. Two risk-neutral suppliers, Supplier 1 and Supplier 2, both own perpetual rights to invest in a new project at asymmetric investment costs $I_{i}$, $i=1,2$, and the project has zero recovery value, i.e., the investment is irreversible. The assumption of the two risk-neutral suppliers is not restrictive. We can instead assume that the two risks inherent in the model can be spanned by some tradable securities in the market as shown by Boyle and Guthrie (2003). Assume the project value of investment follows the geometric Brownian motion as below:

$$
\frac{d V(t)}{V(t)}=(r-\delta) d t+\sigma d W(t), \text { given } V(0)=V,
$$


where the risk-free interest rate $r$, convenience yields $\delta$, and project return volatility $\sigma$ are three constants, and $W$ is a Wiener process. Each supplier can exercise the rights and invest in the project, or delay investment and retain the rights at any time. Investment by the two suppliers may occur sequentially or simultaneously, depending on the payoffs they can receive after investing.

Consider the outcome when the suppliers invest sequentially. The first investor is named as the leader, and the second investor is named as the follower. Before the follower invests, the leader's post-investment payoff is the whole project value of investment $V$, which is the same as the case when the leader is the sole investor. After the follower has invested, the leader's payoff becomes $\left(1+q_{L}\right) V$ and the follower's payoff is $\left(1+q_{F}\right) V$. Since we shed light on the cases where the incentive to preemptive exists, this paper assumes that $-1<q_{F}<q_{L}<$ o unless otherwise specified. This reduced-form set-up is designed to grant the leader a persistent first-mover advantage, thereby motivating the two suppliers to preempt. Although we only focus on the preemptive investment timing game, our model can be employed to analyze the positive externality of investment where larger investment complementarities may lead the two suppliers to invest simultaneously, e.g., Pawlina and Kort (2006) and Carlson et al. (2014). As a result, the two suppliers play a continuous-time investment timing game. We employ the framework of Fudenberg and Tirole (1985), where the two key assumptions underlying the preemption game, among others, are that information lags are very short and that the payoffs are common knowledge.

In addition to the uncertainty of future investment, the two suppliers face the uncertainty of cash flows generated by some existing assets. Through the set-up of Boyle and Guthrie (2003), we simply assume that both suppliers own the same cash holdings $X$ and some existing perpetual assets with the same market value $G$. The existing assets do not reinvest any cash flow so they are constants. In particular, we assume that the two suppliers are subject to asymmetric external financing capabilities, leading to asymmetric liquidity constraints when the two suppliers invest. First, investing the project is possible for the two suppliers, if and only if:

$I_{i} \leq X+G+\alpha_{i}\left(1+q_{k}\right) V, i=1,2, k=L, F$,

The right-hand side of Equation (2) represents the whole funding resources available to each supplier, consisting of cash reserves plus the realizable values of the suppliers' existing assets and external financing capacities on the potential investment project. For the rationale behind this set-up, please refer to Boyle and Guthrie (2003). We further assume that the existence of a rival intensifies a supplier's liquidity constraints no matter whether the supplier is the leader or follower, which is consistent with the results of empirical findings, e.g., Haushalter 
et al. (2008). The two constants $\alpha_{i} \in[0,1)$ show the frictions, capturing the two suppliers' abilities to extract the full project value for outside investors, limit the amount of funding. Since no supplier is pre-determined as a leader or follower and the two suppliers have the same internal financing capacity (initial cash balances plus existing assets), the supplier with a higher external financing capacity, is named as the supplier with higher financing capacity. Lyandres (2007) also emphasizes the effect of external financing on a supplier's optimal investment timing decision.

To investigate the joint effects of asymmetric financing capacities and investment costs on the two suppliers' optimal timing decisions, from Equation (2) we can define the leader's liquidity constraint trigger $\hat{V}_{i, L}^{c m}(X) \equiv$ $\left(I_{i}-X-G\right) /\left(1+q_{L}\right) \alpha_{i}, i=1,2$, which is high as the project value has to be high in order for the leader to have sufficient funds to finance the investment project. The supplier with a smaller liquidity constraint trigger $\left(I_{i}-X-G\right) / \alpha_{i}$, which can result from a lower investment cost or/and a higher external financing capacity, is named as the less liquidity constrained supplier hereafter.

The two suppliers' cash balances are assumed to vary over time according to:

$d X(t)=r X(t) d t+v d t+\phi d B(t)$,

where $v$ and $\phi$ are constants and $B$ is another Wiener process with $d W(t) d B(t)=\rho d t$. The first term of the right-hand side in Equation (3) is the amount obtained from investing cash in riskless securities, and the other terms show the uncertain cash flows generated by the suppliers' existing assets. Notice that $G=v / r$.

Next, we assume that when a shortage of the two suppliers' cash reserves occurs, $X<0$, both suppliers will face cash deficits. If the cash deficits of the suppliers exceed the realizable value of the suppliers' non-cash assets and external financing capacity, then the suppliers must be liquidated and sell out the options to invest. Notice that both suppliers can be the leader or follower. As a consequence, Supplier $i, i=1,2$, will be forced to liquidate if $X+G+L_{i}^{u}\left(\alpha_{i}\left(1+q_{L}\right) V\right) \leq 0$, when Supplier $i$ is the leader and forced to liquidate if $\boldsymbol{X}+\boldsymbol{G}+\boldsymbol{F}_{i}^{u}\left(\alpha_{i}\left(\mathbf{1}+q_{F}\right) \boldsymbol{V}\right) \leq \mathbf{O}$ when Supplier $i$ is the follower, where $\boldsymbol{L}_{i}^{u}$ and $F_{i}^{u}$ respectively denote the values of options to invest for the leader and follower when the two suppliers are not liquidity constrained. Following Boyle and Guthrie (2003), we assume that the projects of the two suppliers possess some unique features so that the options to invest are not fully transferable. We respectively denote the values of options to invest for the leader and follower as $L_{i}^{c}$ and $F_{i}^{c}$, $i=1,2$, when the two suppliers are liquidity constrained. It is noteworthy that the constrained real options values should converge to their corresponding 
unconstrained real options values when the risk of future funding shortfalls disappears, i.e., $\lim _{X \rightarrow \infty} L_{i}^{c}(X, V)=L_{i}^{u}(V)$ and $\lim _{X \rightarrow \infty} F_{i}^{c}(X, V)=F_{i}^{u}(V)$. At the same time, the constrained investment decisions of the leader and follower, $\hat{V}_{i, L}^{c}(X)$ and $\hat{V}_{i, F}^{c}(X)$, converge to their corresponding unconstrained investment policies, $\hat{V}_{i, L}^{u}$ and $\hat{V}_{i, F}^{u}$, respectively, i.e., $\lim _{X \rightarrow \infty} \hat{V}_{i, L}^{c}(X)=\hat{V}_{i, L}^{u}$ and $\lim _{X \rightarrow \infty} \hat{V}_{i, F}^{c}(X)=\hat{V}_{i, F}^{u}$. For the further analysis of liquidity constrained suppliers in the next section, Appendix A provides the optimal investment triggers and value functions of the leader and follower when the suppliers are liquidity unconstrained in an asymmetric duopoly.

\section{Optimal investment decisions when suppliers are liquidity constrained in an asymmetric duopoly}

To gain a better understanding of the impact of liquidity constraints on the investment timing, we first review Boyle and Guthrie (2003) where a single supplier facing investment opportunity is liquidity constrained. Then we outline the problems of optimal investment timing decisions when the two suppliers are subject to asymmetric liquidity constraints in duopoly.

\subsection{Review of Boyle and Guthrie (2003)}

We assume there is only a monopolistic supplier (without loss of generality, denoted as Supplier 1) facing this investment project. When Supplier 1 is liquidity constrained, the Supplier 1's optimal investment policy is the same as the findings of Boyle and Guthrie (2003). Because the real options values of monopolistic Supplier $1, M_{1}^{c}(X, V)$, is a function of $X$ and $V$, the corresponding optimal investment decisions $\hat{V}_{1, M}^{c}(X)$ must also be functions of $X$, rather than constants as in the case of the unconstrained supplier.

The real options values with liquidity constraints therefore satisfy the following partial differential equation (PDE) and boundary conditions:

$$
\begin{aligned}
& \frac{1}{2} \sigma^{2} V^{2} \frac{\partial^{2} M_{1}^{c}}{\partial V^{2}}+\rho \sigma \phi V \frac{\partial^{2} M_{1}^{c}}{\partial V \partial X}+\frac{1}{2} \phi^{2} \frac{\partial^{2} M_{1}^{c}}{\partial X^{2}}+(r-\delta) V \frac{\partial M_{1}^{c}}{\partial V}+r(X+G) \frac{\partial M_{1}^{c}}{\partial X}-r M_{1}^{c}=0 \\
& \lim _{X \uparrow \infty} M_{1}^{c}(X, V)=M_{1}^{u}(V)=\left(\hat{V}_{1, M}^{u}-I_{1}\right)\left(V / \hat{V}_{1, M}^{u}\right)^{\beta} \\
& \lim _{V \uparrow \hat{V}_{1, M}^{c}(X)} M_{1}^{c}(X, V)=\hat{V}_{1, M}^{c}(X)-I_{1} \\
& \lim _{X \downarrow \bar{X}_{M}(V)} M_{1}^{c}(X, V)=M_{1}^{u}\left(\alpha_{1} V\right), \text { and } \lim _{V \downarrow 0} M_{1}^{c}(X, V)=0 .
\end{aligned}
$$

For details of the derivation, please refer to Appendix A of Boyle and Guthrie (2003). 
Equation (5) shows that the real options values in consideration of liquidity constraints converge to their unconstrained values as the cash balance goes to infinity where $M_{1}^{u}(V)$ is the real option of the unconstrained monopolist, $\hat{V}_{1, M}^{u}$ is the investment trigger when the monopolist is unconstrained and $\beta=\left[\sigma^{2}+(r-\delta)\right] / 2 \sigma^{2}+\sqrt{\left(2 r / \sigma^{2}\right)+\left\{\left[\sigma^{2}+(r-\delta)\right] / 2 \sigma^{2}\right\}^{2}}$. Equation (6) illustrates that the firm will invest when the project value is high enough, whereby $\hat{V}_{1, M}^{c}(X)$ denotes the firm's optimal investment trigger depending on the firm's cash balance when the firm is constrained, and as the cash balance goes to infinity the firm's investment trigger converges to its unconstrained counterpart $\lim _{X \uparrow \infty} \hat{V}_{1, M}^{c}(X) \equiv \hat{V}_{1, M}^{u}=\beta I_{1} /(\beta-1)$. Equation (7) demonstrates the supplier's liquidation constraint is binding when the cash balance is low enough, and the follower's real options values become worthless as the underlying project value goes to zero, where $\bar{X}_{M}(V)$ is the supplier's liquidation trigger of cash balance determined by the first time that $X+G+M_{1}^{u}\left(\alpha_{1} V\right) \leq 0$.

Following Boyle and Guthrie (2003), we use a finite difference method with parameters of $I_{1}=G=100, \sigma=0.3, r=\delta=0.03, \rho=0.5, \phi=80$, and $\alpha_{1}=0.8$, and employ Figure 1 (similar to Figure 1 of Boyle and Guthrie, 2003) so as to underline the effects of liquidity constraints on Supplier 1's optimal investment decisions and Supplier 1 makes the decisions as it exclusively owns the right to invest in this project. Appendix B details the numerical procedure.

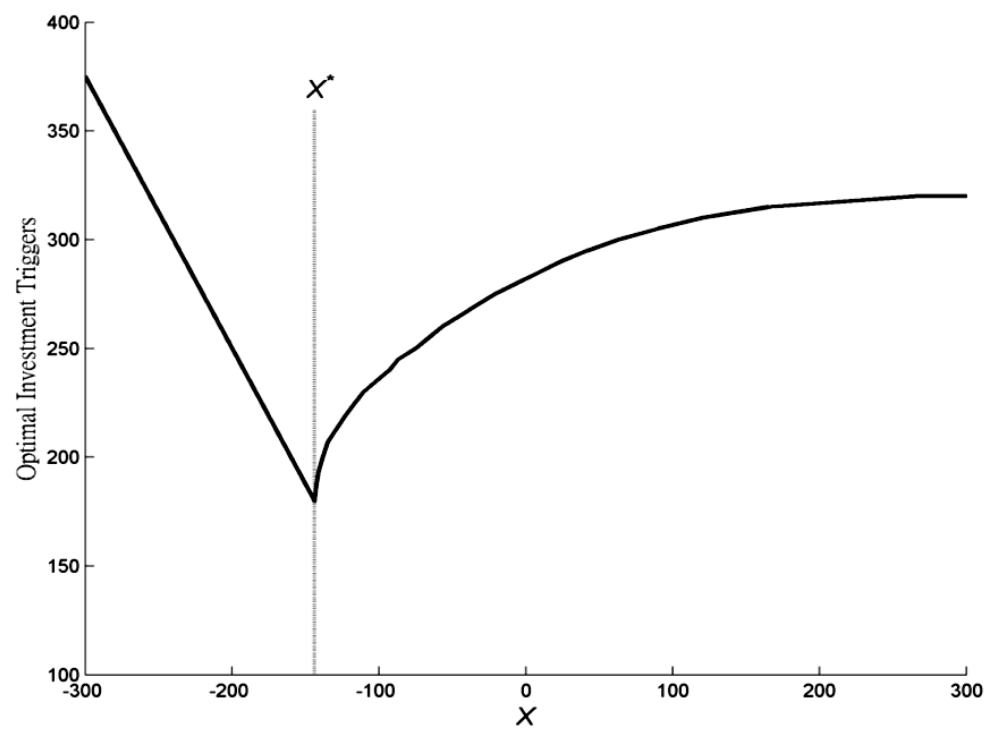

Figure 1. Optimal investment triggers when the supplier is liquidity constrained in a monopoly 
This figure 1 demonstrates the optimal investment triggers in a monopoly with liquidity constraint. The pattern is exactly the same as that of Boyle and Guthrie (2003). The investment cost I and the market values of existing assets $G$ are both assumed to be 100 . The other parameters are given by $r=\delta=0.03, \alpha_{1}=0.8$, $\sigma=0.3, \rho=0.5$ and $\phi=80$.

Supplier 1's optimal investment trigger is basically V-shaped. The left-hand side of the V-shape shows the effect of financing constraints on Supplier 1's investment decisions. In low states of $X$ (when $X<X^{*}$ ), that is the risk of future funding shortfalls is relatively high, the risk of delaying investment is so large that the supplier tends to invest as soon as it has enough funds to do so. In the right-hand side of the V-shape, the risk of future funding shortfalls is reduced, and the possibility that the supplier will have insufficient funds to finance the project in the future drops. Therefore, the supplier starts to enjoy its wait-and-see option and gradually raises its investment threshold in high states of $X$ (when $X>X^{*}$ ). Finally, if $X$ goes up enough, then the optimal investment trigger converges to the optimal investment decision when Supplier 1 is liquidity unconstrained.

\subsection{Optimal investment timing decisions when the two asymmetric suppliers are liquidity constrained}

The investment decisions of the constrained suppliers in a duopoly are more complicated, because the decisions of the two suppliers are relevant to each other. The continuous-time leader-follower timing game is solved backwards. First of all, we consider the optimal investment decision of the follower. The follower's real options value $F_{i}^{c}(X, V), i=1,2$, after the leader has invested is governed by the following PDE and boundary conditions:

$$
\frac{1}{2} \sigma^{2} V^{2} \frac{\partial^{2} F_{i}^{c}}{\partial V^{2}}+\rho \sigma \phi V \frac{\partial^{2} F_{i}^{c}}{\partial V \partial X}+\frac{1}{2} \phi^{2} \frac{\partial^{2} F_{i}^{c}}{\partial X^{2}}+(r-\delta) V \frac{\partial F_{i}^{c}}{\partial V}+r(X+G) \frac{\partial F_{i}^{c}}{\partial X}-r F_{i}^{c}=0
$$

$\lim _{X \uparrow \infty} F_{i}^{c}(X, V)=F_{i}^{u}(V)$,

$\lim _{V \uparrow \hat{V}_{i, F}^{c}(X)} F_{i}^{c}(X, V)=\left(1+q_{F}\right) \hat{V}_{i, F}^{c}(X)-I_{i}$,

$\lim _{X \downarrow \bar{X}_{F_{i}}(V)} F_{i}^{c}(X, V)=F_{i}^{u}\left(\alpha_{i}\left(1+q_{F}\right) V\right)$ and $\lim _{V \downarrow 0} F_{i}^{c}(X, V)=0$.

Equations (9) and (11) share the same explanations as those in Equations (5) and (7) where $F_{i}^{u}(V)$ is the real option value of Supplier $i$ without liquidity constraint if Supplier $i$ is the follower, and $\bar{X}_{F_{i}}(V)$ is the follower's liquidation trigger of its cash balance determined by the first time that $X+G+F_{i}^{u}\left(\alpha_{i}\left(1+q_{F}\right) V\right) \leq 0$. Equation $(10)$ is the value-matching condition showing that the follower's real 
options value is indifferent before and after its investment. Solving this PDE by the finite difference method yields a $V$-shaped optimal investment trigger for the follower, $\hat{V}_{i, F}^{c}(X)$, which is similar to the case of a single supplier as demonstrated in Figure 1.

Second, the leader's investment value after the leader has invested is denoted as $L_{i}^{c}(X, V)$, which has to account for the adjustment value when the follower invests. Here, $L_{i}^{c}(X, V)$ is governed by the following PDE and boundary conditions:

$$
\begin{aligned}
& \frac{1}{2} \sigma^{2} V^{2} \frac{\partial^{2} L_{i}^{c}}{\partial V^{2}}+\rho \sigma \phi V \frac{\partial^{2} L_{i}^{c}}{\partial V \partial X}+\frac{1}{2} \phi^{2} \frac{\partial^{2} L_{i}^{c}}{\partial X^{2}}+(r-\delta) V \frac{\partial L_{i}^{c}}{\partial V}+r(X+G) \frac{\partial L_{i}^{c}}{\partial X_{i}}+\delta V-r L_{i}^{c}=0^{\prime} \\
& \lim _{X \uparrow \infty} L_{i}^{c}(X, V)=L_{i}^{u}(V)=V+q_{L} \hat{V}_{j, F}^{u}\left(\frac{V}{\hat{V}_{j, F}^{u}}\right)^{\beta_{1}}, \\
& \lim _{V \uparrow \hat{V}_{j, F}^{c}(X)} L_{i}^{c}(X, V)=\left(1+q_{L}\right) \hat{V}_{j, F}^{c}(X), \\
& \lim _{X \downarrow X_{L_{i}}(V)} L_{i}^{c}(X, V)=\alpha_{i}\left(1+q_{L}\right) V \text { and } \lim _{V \downarrow 0} L_{i}^{c}(X, V)=0 .
\end{aligned}
$$

Equations (13) and (15) share the similar explanations as those in Equations (5) and (7) where $L_{i}^{u}(V)$ is the leader's investment value after the leader has invested without financing constraint, $\hat{V}_{j, F}^{u}$ is the investment trigger of the competitor Supplier $j$ without financing constraint where Supplier $j$ is the follower, and $\bar{X}_{L_{i}}(V)$ is the leader's liquidation trigger of its cash balance determined by the first time that $X+G+\alpha_{i}\left(1+q_{L}\right) V \leq 0$ after the investment of the leader and before the investment of the follower. Equation (14) is the value-matching condition showing that the leader's immediate investment value is indifferent before and after the follower's investment.

Third and finally, the real options value of the leader $L_{i}^{c}(X, V)$ before the leader investment is governed by the following PDE and boundary conditions:

$$
\begin{aligned}
& \frac{1}{2} \sigma^{2} V^{2} \frac{\partial^{2} L_{i}^{c}}{\partial V^{2}}+\rho \sigma \phi V \frac{\partial^{2} L_{i}^{c}}{\partial V \partial X}+\frac{1}{2} \phi^{2} \frac{\partial^{2} L_{i}^{c}}{\partial X^{2}}+(r-\delta) V \frac{\partial L_{i}^{c}}{\partial V}+r(X+G) \frac{\partial L_{i}^{c}}{\partial X}-r L_{i}^{c}=0 \\
& \lim _{X \rightarrow \infty} L_{i}^{c}(X, V)=L_{i}^{u}(V) \\
& \lim _{V \rightarrow \hat{V}_{i, L}^{c}(X)} L_{i}^{c}(X, V)=L_{i}^{c}\left(X, \hat{V}_{i, L}^{c}(X)\right)-I_{i}
\end{aligned}
$$


$\lim _{X \rightarrow \bar{X}_{L_{i}}(V)} L_{i}^{c}(X, V)=L_{i}^{u}\left(\alpha_{i}\left(1+q_{L}\right) V\right)$, and $\lim _{V \rightarrow 0} L_{i}^{c}(X, V)=0$

Equations (17) and (19) again share the same explanations as those in Equations (5) and (7) where $L_{i}^{u}(V)$ is the real option of Supplier $i$ without liquidity constraint if Supplier $i$ is the leader and $\bar{X}_{L_{i}}(V)$ is the leader's liquidation trigger of its cash balance determined by the first time that $X+G+L_{i}^{u}\left(\alpha_{i}\left(1+q_{L}\right) V\right) \leq 0$ before the investment of the leader. Equation (18) is the value-matching condition showing that the leader's investment value is indifferent before and after its investment. Solving this PDE by the finite difference method yields a V-shaped optimal investment trigger, $\hat{V}_{i, L}^{c}(X)$.

We next define the earliest investment timing under which Supplier $i$ still has an incentive to preempt as the leader when the two suppliers are subject to asymmetric liquidity constraints. Let $\hat{V}_{i, P}^{c}(X)$ be the smallest solution of $F_{i}^{c}\left(X, \hat{V}_{i, P}^{c}(X)\right)=L_{i}^{c}\left(X, \hat{V}_{i, P}^{c}(X)\right)-I_{i}$ for a given $X, i=1,2$. Since the two suppliers are liquidity constrained, each supplier's preemptive investment decision is not attainable when the shortage of the cash reserve is too large. We therefore refine the two suppliers' preemptive investment triggers as $\hat{V}_{i, P}^{c m}(X)=\max \left(\hat{V}_{i, P}^{c}(X), \hat{V}_{i, L}^{c m}(X)\right)$ to account for this unattainability, where $\hat{V}_{i, L}^{c m}(X) \equiv\left(I_{i}-G-X\right) /\left(\alpha_{i}\left(1+q_{L}\right)\right)$, the liquidity constraint trigger, is high as the project value has to be high in order for the leader to have sufficient funds to finance the investment project. When $\hat{V}_{i, P}^{c}(X)$ is smaller than $\hat{V}_{i, L}^{c m}(X)$, Supplier $i$ cannot preempt to invest due to its own liquidity constraint and can make a preemptive investment only when the project value is at least larger than $\hat{V}_{i, L}^{c m}(X)$.

To determine which supplier tends to be the leader, we have to compare $\hat{V}_{i, L}^{c}(X)$ and $\hat{V}_{i, P}^{c m}(X)$ for each $X$ of the two suppliers. Following Pawlina and Kort (2006) and Carlson et al. (2014), we analyze the equilibria of this two-player investment timing game in the case that the two suppliers have asymmetric investment costs and liquidity constraints. First, the leader of the investment timing game is endogenously determined by which supplier has a greater incentive to invest the project earlier. As a consequence, if $\min \left(\hat{V}_{1, L}^{c}(X), \hat{V}_{2, L}^{c}(X), \hat{V}_{1, P}^{c m}(X), \hat{V}_{2, P}^{c m}(X)\right)=\hat{V}_{i, L}^{c}(X)$ or $\hat{V}_{i, P}^{c m}(X)$, then Supplier $i$ is the leader and Supplier $j$ is the follower, where $i, j=1,2$ and $i \neq j$. Second, given the determined roles, the leader Supplier $i$ must consider the potential preemptive investment of the follower, thereby choosing 
$\min \left(\hat{V}_{i, L}^{c}(X), \hat{V}_{j, P}^{c m}(X)\right)$ as its the optimal investment timing decision, while the follower Supplier $j$ chooses $\hat{V}_{j, F}^{c}(X)$. When the leader Supplier $i$ chooses $\hat{V}_{i, L}^{c}(X)\left(\hat{V}_{j, P}^{c m}(X)\right)$ and the follower Supplier $j$ chooses $\hat{V}_{j, F}^{c}(X)$, the equilibrium is named as the nonpreemptive (preemptive) leader-follower equilibrium.

\section{Numerical analyses and implications}

In this section we present some numerical analyses of our model, which provide some interesting financial and economic insights. We utilize the numerical procedure introduced in Appendix B and employ the rule of the game equilibrium mentioned in the last section. The basic parameters employed here are consistent with those in Boyle and Guthrie (2003), and the choices of $q_{L}$ and $q_{F}$ are arbitrary and not relevant to our main findings.

To completely explore our analyses, without loss of generality, we index the supplier with a cost advantage (lower investment cost) as Supplier 1 and the supplier with a cost disadvantage (higher investment cost) as Supplier 2, i.e., $I_{1}<I_{2}$ is given. We then investigate the impacts of asymmetric financing capacities on the optimal investment timing decisions when the financing capacity of Supplier 1 is higher than that of Supplier 2 and when the financing capacity of Supplier 1 is lower than that of Supplier 2, respectively. In order to clarify our numerical results, we investigate the impacts due to the different degrees of asymmetric financing capacities on the optimal investment timing decisions when the cost asymmetry between the two suppliers is large and small. We focus on the two strictly asymmetric cases. However, when the two suppliers are symmetric in investment costs or liquidity constraints, the investment timing game of the two identical suppliers can lead to random leader-follower equilibrium where there are some probabilities that Supplier 1 is the leader while Supplier 2 is the follower, and vice versa for a given $X$. Moreover, the probability of a mistake under which the two suppliers invest simultaneously is zero.

\subsection{The effects of asymmetric financing capacities and investment costs on investment timing decisions when the cost asymmetry is large}

Figure 2 demonstrates the optimal investment decisions of the two-player investment timing game when Supplier 2 is facing a large cost disadvantage, where Panel A presents the case that the financing capacity of Supplier 1 is higher ( $\left.\alpha_{2}=0.5<\alpha_{1}=0.8\right)$ and Panel B shows the case that the financing capacity of Supplier 2 is higher $\left(\alpha_{2}=1>\alpha_{1}=0.8\right)$, given that Supplier 2 faces a large cost disadvantage. The parameters are given by $G=100, q_{L}=-0.45, q_{F}=-0.55$ $, r=\delta=0.03, \sigma=0.3, \rho=0.5, \phi=80, I_{1}=100$ and $I_{2}=150$. In terms 
of asymmetric liquidity constraints, Panel A shows that $\left(I_{1}-X-G\right) / \alpha_{1}$ $<\left(I_{2}-X-G\right) / \alpha_{2}$ for all $X$, demonstrating that Supplier 2, which is facing cost disadvantage and lower financing capacity, is surely more liquidity constrained than Supplier 1. On the other hand, Panel B shows that $\left(I_{1}-X-G\right) / \alpha_{1}>\left(I_{2}-X-G\right) / \alpha_{2}$ when $X<X_{C}$ and $\left(I_{1}-X-G\right) / \alpha_{1}$ $<\left(I_{2}-X-G\right) / \alpha_{2}$ when $X>X_{C}$. Supplier 2, which is facing cost disadvantage and higher financing capacity, is less (more) liquidity constrained when the risk of future funding shortfalls is relatively high (low).

In view of Panel A, Supplier 1 is always the leader while Supplier 2 is always the follower. This is intuitive since Supplier 1 has two significant advantages over Supplier 2 in investment costs and financing capacities. Panel B demonstrates that with higher financing capacity Supplier 2 tends to be the leader when the risk of future funding shortfalls is relatively high (when $X<X_{C}$ ), whereas with cost advantage Supplier 1 tends to be the leader when the risk of future funding shortfalls is relatively low (when $X>X_{C}$ ).

Figure 2 shows that with higher financing capacity the supplier tends to be the leader when the risk of future funding shortfalls is relatively high, and it still holds even when the supplier faces a large cost disadvantage. Most studies in the real options literature predict that the low-cost (high-tech) supplier tends to be the leader when enjoying some first-mover advantages. Our model further demonstrates that the high-cost supplier with less financing constraints can be the leader when the risk of future funding shortfalls is so high that the less financing constrained effect dominates the high cost effect.

On the other hand, with cost advantage the supplier tends to be the leader when the risk of future funding shortfalls is relatively low. As a consequence, the roles of leader and follower in an investment opportunity are jointly determined by the relative investment costs and financing capacities, and the risk of future funding shortfalls. Besides, comparing Panel A with Panel B, a significant improvement in Supplier 2's financing capacities (a larger increase in $\alpha_{2}$ ) alters the role of Supplier 2 from a follower to a leader when the risk of future funding shortfalls is relatively high, whereas the role of Supplier 2 is not changed when the risk of future funding shortfalls is relatively low. As a result, Panels A and B of Figure 2 together demonstrate that in addition to the asymmetric investment costs, the asymmetric financing capacities between the two suppliers crucially impact the roles of leader and follower and their optimal investment timing decisions. This result complements the findings of Haushalter et al. (2008), Fresard (2010), and Schroth and Szalay (2010).

Panel A of this figure shows that Supplier 2, which faces a large cost disadvantage and lower financing capacity, always tends to be the follower. Panel $B$ of this figure 


\section{Manoj KUMAR}

demonstrates that even with a large cost disadvantage Supplier 2, which has higher financing capacity, can tend to be the leader when the risk of future funding short falls is relatively high (when $X<X_{C}$ ). The parameters are given by $G=100$, $q_{L}=-0.45, q_{F}=-0.55, r=\delta=0.03, \alpha_{1}=0.8, \sigma=0.3, \rho=0.5$, $\phi=80, I_{1}=100, I_{2}=150$, and $\alpha_{2}=0.5$ (Panel A) and $\alpha_{2}=1$ (Panel B).

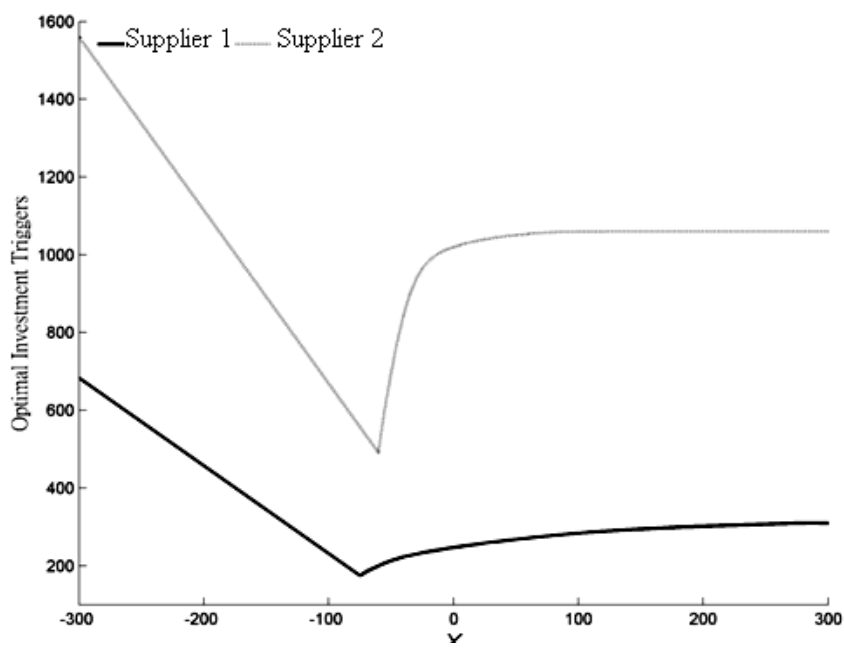

Panel A. Supplier 1 has a higher financing capacity

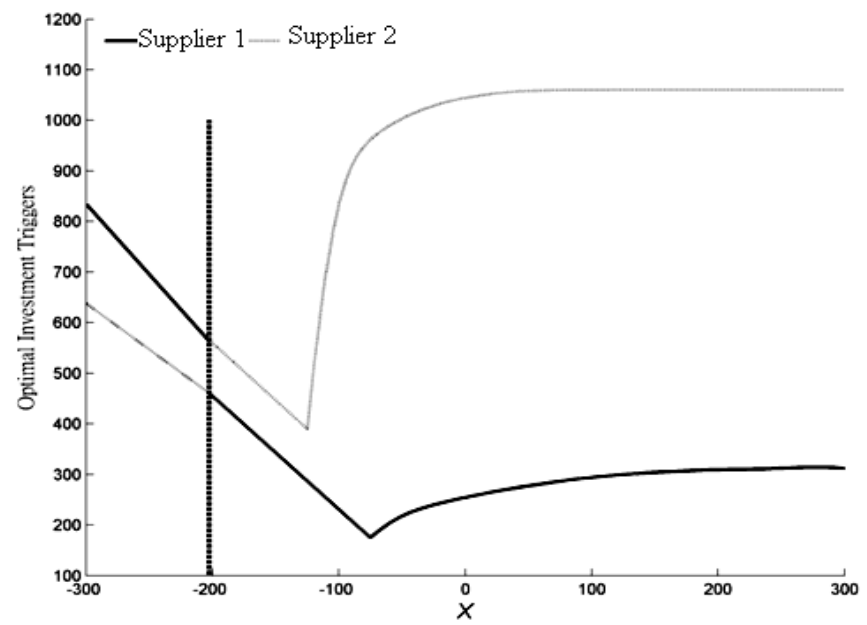

Panel B: Supplier 2 has a higher financing capacity

Figure 2. The effects of asymmetric financing capacities and investment costs on optimal investment triggers when the cost asymmetry between the two suppliers is large 


\subsection{The effects of asymmetric financing capacities and investment costs on investment timing decisions when the cost asymmetry is small}

Figure 3 mainly illustrates the effects of asymmetric financing capacities on the two suppliers' optimal investment timing decisions when Supplier 2 is facing a small cost disadvantage $\left(I_{1}=100<I_{2}=103\right.$ ). Panel A of Figure 3 demonstrates the case that Supplier 2 faces significantly lower financing capacity ( $\alpha_{1}=0.8>\alpha_{2}=0.5$ ), and shows that when the risk of future funding shortfalls is relatively high (when $X<X_{C}^{L}$ ), Supplier 1 is the leader while Supplier 2 is the follower due to their relative financing capacities. When the risk of future funding shortfalls is intermediate (when $X_{C}^{L}<X<X_{C}^{H}$ ), with higher financing capacity Supplier 1 tends to be the follower while Supplier 2 becomes the leader. In this region, the Supplier 1's incentive to be the leader has been weakened much more by its desire to enjoy the wait-and-see option, whereas the investment incentive of Supplier 2 is still dominated by its significant liquidity constraints due to its significant lower financing capacity. As the risk of future funding shortfalls turns relatively low (when $X>X_{C}^{H}$ ), the effects of asymmetric financing capacities on the two suppliers' optimal investment decisions vanish. At the same time, the effect of the small cost disadvantage becomes dominant, thereby leading to Supplier 1 again as the leader and Supplier 2 as the follower.

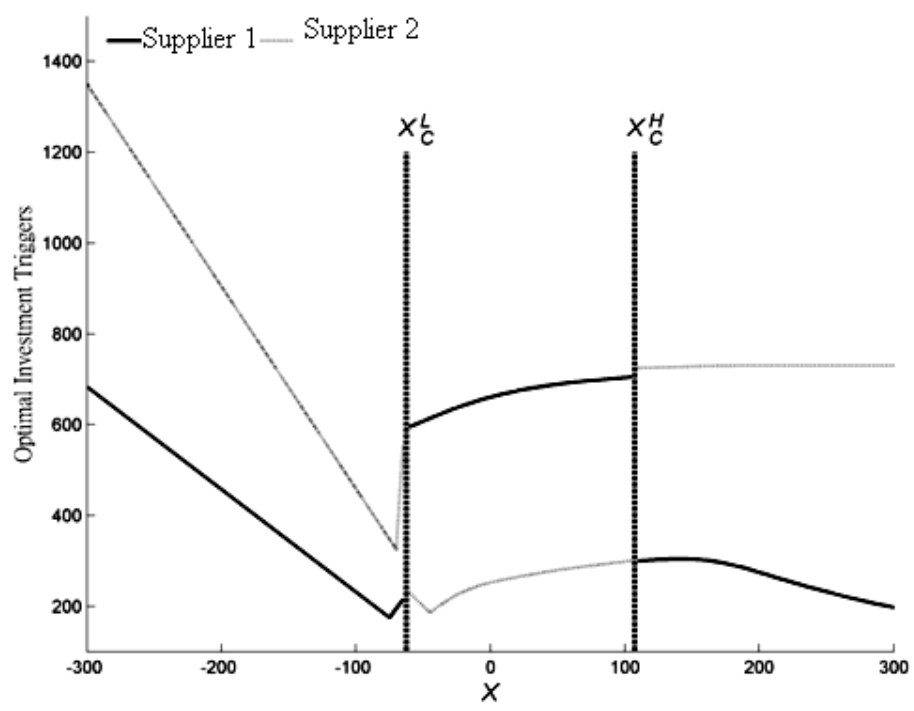

Panel A. Supplier 1 has a higher financing capacity 
Manoj KUMAR

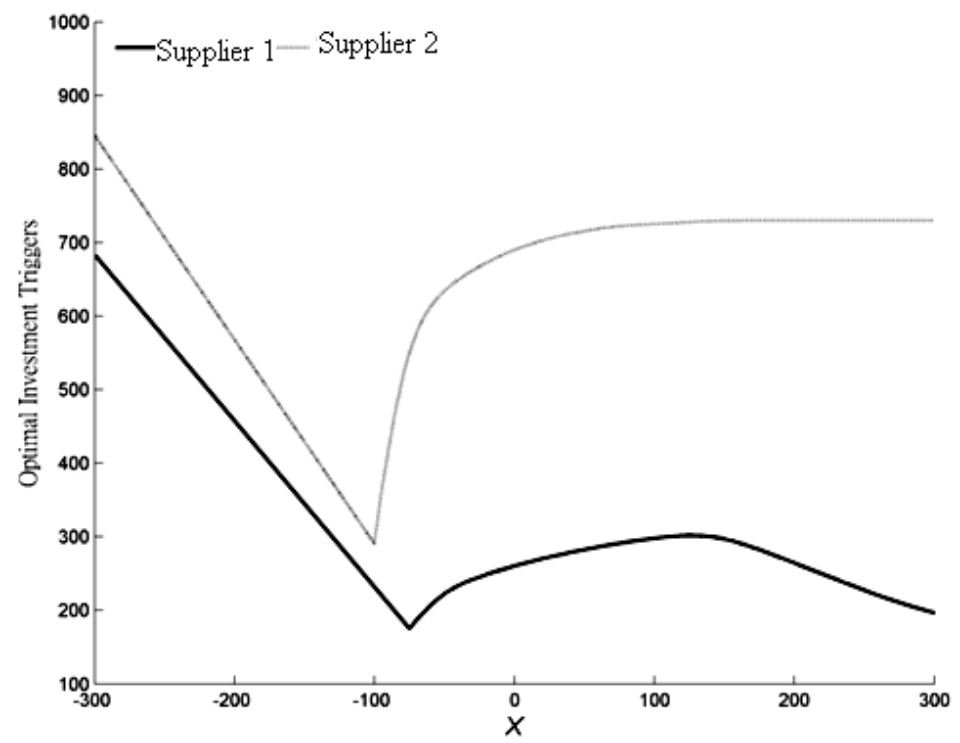

Panel B. The two suppliers have the same financing capacity

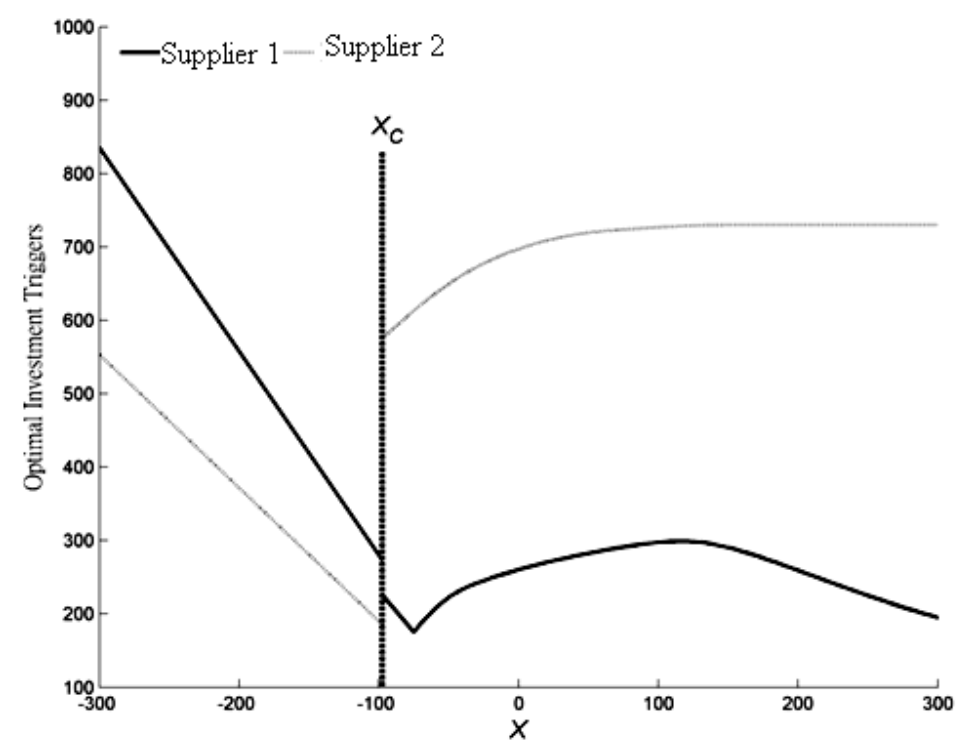

Panel C. Supplier 2 has a higher financing capacity

Figure 3. The effects of asymmetric financing capacities and investment costs on optimal investment triggers when the cost asymmetry between the two suppliers is small 
Given that the investment cost of Supplier 1 ( $\left.I_{1}=100\right)$ is slightly less than that of Supplier $2\left(I_{2}=103\right)$, in Panel A Supplier 2 has a significant lower financing capacity $\left(\alpha_{2}=0.5\right)$, in Panel B the two suppliers have the same financing capacities where Supplier 2 is slightly more liquidity constrained ( $\alpha_{2}=0.8$ ), and in Panel $\mathrm{C}$ Supplier 2 has a higher financing capacity $\left(\alpha_{2}=1\right)$. Panel A shows that Supplier 2, which faces a small cost disadvantage and a lower financing capacity, can be the leader. Compared with Panel A, Panel B shows that when the financing capacity of Supplier 2 improves significantly and equals to that of Supplier 1, and Supplier 2 cannot be the leader anymore where Supplier 2 is still slightly more liquidity constrained than Supplier 1 . Panel $C$ demonstrates that when the risk of future funding shortfalls is relatively high, with higher financing capacity Supplier 2 tends to be the leader, while when the risk of future funding shortfalls is relatively low, with a cost advantage Supplier 1 tends to be the leader. Other parameters are given by $G=100, q_{L}=-0.45, q_{F}=-0.55, \sigma=0.3, r=\delta=0.03$, $\alpha_{1}=0.8, \rho=0.5$ and $\phi=80$.

What we particularly observe in Panel A of Figure 3 is a weaker supplier that faces significant lower financing capacity and a small cost disadvantage can even be the leader under some degree of the risk of future funding shortfalls. The main reason is that when the supplier with a higher financing capacity starts to enjoy the flexibility of waiting and delays its investment timing, the risk of delaying investment for the supplier with a lower financing capacity is still so high that its optimal investment decision is to invest as soon as possible. As a consequence, the supplier with a higher financing capacity and small cost advantage voluntarily delays investment and becomes the follower, while the supplier with a lower financing capacity and small cost disadvantage accelerates investment and becomes the leader. This complements the findings of Munos (2009), who provides the evidence that the fraction of approved new drugs from large pharmaceutical supplier is getting decreasing from $75 \%$ in the early 1980 s to roughly $35 \%$ in 2008 . Meanwhile, the fraction of small biotechnology and pharmaceutical suppliers (usually with lower financing capacities) rises up from $23 \%$ to nearly $70 \%$. Our model suggests that small suppliers even with a small cost disadvantage can win innovation races (become the leader). In fact, we have also provided another explanation why a small supplier (with a lower financing capacity) can be the leader. In Panel B of Figure 2, if the risk of future funding shortfalls is relatively low, a small supplier with a cost advantage can also be the leader. Furthermore, in Panel A of Figure 3, we show that a small supplier with a small cost disadvantage can be the leader when the risk of future funding shortfalls is intermediate.

In Panel B of Figure 3, the financing capacity of Supplier 2, $\alpha_{2}$, improves from 0.5 to 0.8 , and Supplier 2 is thus subject to the same financing capacity as Supplier 1 
$\left(\alpha_{1}=\alpha_{2}\right)$, whereas Supplier 2 is always slightly more liquidity constrained than Supplier 1 due to the Supplier 2's small cost disadvantage. Panel B shows that Supplier 2 is always being the follower, which is similar to Panel A of Figure 2. In Figure 3, comparing Panel A with Panel B, when the financing capacity of Supplier $2, \alpha_{2}$, improves and closes to that of the rival Supplier $1, \alpha_{1}$, (while Supplier 2 is still slightly more liquidity constrained than Supplier 1 ) contrary to simple intuition, Supplier 2 cannot be the leader anymore, other things being equal. The reason is that when the asymmetry between the liquidity constraints of the two suppliers is small, the timings for when the two suppliers start to enjoy waiting are so close that Supplier 2 has no chance to be the leader.

In Panel $\mathrm{C}$ of Figure 3, with the same small cost disadvantage, we further increase the financing capacity of Supplier $2 \alpha_{2}$ to be 1 , and therefore the financing capacity of Supplier 2 becomes higher than that of Supplier 1 . Panel $C$ here is similar to Panel B of Figure 2, where Supplier 2 with a higher financing capacity is the leader when the risk of future funding shortfalls is relatively high (when $X<X_{C}$ ), and Supplier 1 with a cost advantage is the leader when the risk of future funding shortfalls is relatively low (when $X>X_{C}$ ). According to unreported numerical results, if Supplier 2 faces a slightly higher financing capacity and a small cost disadvantage, then the results still indicate that Supplier 2 is the leader when the risk of future funding shortfalls is relatively high, while Supplier 1 is the leader when the risk of future funding shortfalls is relatively low.

Finally, all three panels of Figure 3 also demonstrate how the interaction between liquidity constraints and preemption affects the suppliers' optimal investment timing decisions. They all show that the threat of the follower's preemptive investment generates a negative sensitivity for a supplier's optimal investment trigger to the cash balance when the risk of future funding shortfalls is low. In addition, only when the risk of future funding shortfalls is low, small asymmetry of investment costs leads to effective preemption. This complements the result of Pawlina and Kort (2006) in which the low-cost supplier preempts the high-cost supplier when the asymmetry of investment cost is small.

\subsection{Investment and uncertainty}

Our model also contributes to the effect of project return volatility on the roles of leader and follower and the relationship between investment and uncertainty. When investment is liquidity unconstrained, the real options literature often shows that the change in project return volatility always has no effect on the roles of leader and follower. The greater uncertainty in the investment project value increases the value of waiting, thereby raising the optimal investment trigger and deferring the timing of investment. However, we show that the change in return volatility can alter the roles of leader and follower when investment is subject to 
liquidity constraints, and further illustrate that the effect of project return volatility on the optimal investment trigger is ambiguous in an asymmetric duopoly. Boyle and Guthrie (2003) demonstrate that greater uncertainty in current cash flow decreases the value of waiting and thus lowers the optimal investment trigger, since it increases the possibility of a future funding shortfall.

Figure 4 illustrates the case similar to Panel B in Figure 2 for $\sigma=0.2$ and $\sigma=0.4$. Recalling from Panel B of Figure 2, with a cost advantage Supplier 1 is the leader when the risk of future funding shortfalls is low, while Supplier 2 with a higher financing capacity is the leader when the risk of future funding shortfalls is high. We demonstrate that higher project return volatility makes Supplier 2 become the follower earlier, i.e., the region that Supplier 1 is the leader and Supplier 2 is the follower becomes larger. The reason is that higher project return volatility increases the wait-and-see option value of Supplier 2 more significantly than that of Supplier 1, since Supplier 2 faces a higher financing capacity. Therefore, Supplier 2 starts to enjoy wait-and-see flexibility earlier instead of investing as soon as it has enough funds to do so.

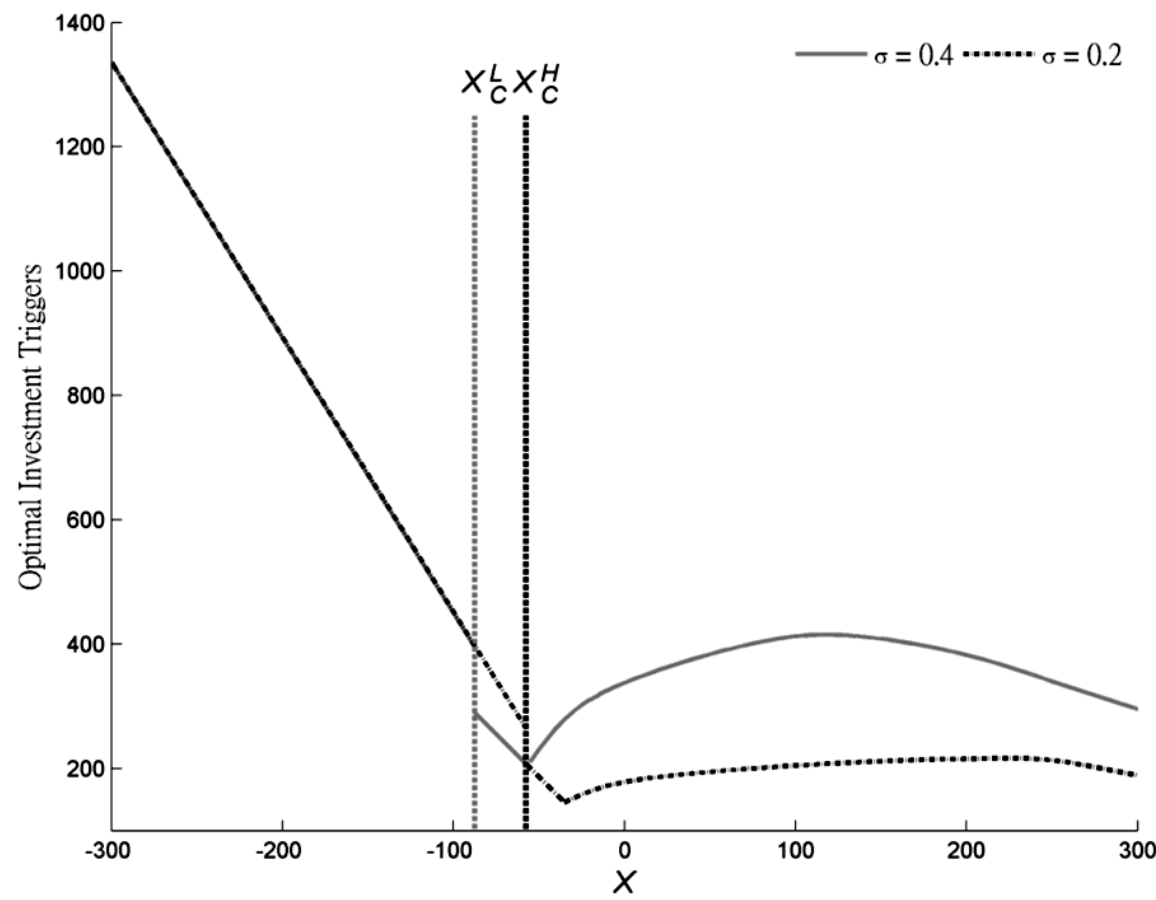

Figure 4. The effects of project return volatility on optimal investment triggers

This figure illustrates how the project return volatility (uncertainty) affects Supplier 1 's optimal investment timing for $\sigma=0.2$ and $\sigma=0.4$. We especially show that 
when $X$ is between $X_{C}^{L}$ and $X_{C}^{H}$, Supplier 1 changes its role from a follower to a leader and Supplier 2 changes its role from a leader to a follower as the project return volatility rises from 0.2 to 0.4 . Moreover, the increase in project return volatility can make the Supplier 1's optimal investment trigger unchanged, higher, or even lower. Other parameters are given by $I_{1}=G=100, I_{2}=120$, $q_{L}=-0.45, q_{F}=-0.55, r=\delta=0.03, \rho=0.5, \phi=80, \alpha_{1}=0.5$ and $\alpha_{2}=0.8$.

Figure 4 particularly posits out that there are three regions showing three different impacts of project return volatility on Supplier 1's optimal investment trigger. The left region (when $X<X_{C}^{L}$ ) presents that project return volatility has no impact on Supplier 1's optimal investment trigger because the liquidity constraints of the two suppliers are binding. In this region, Firm 1 (2) is always the follower (leader) when $\sigma=0.2$ and $\sigma=0.4$. The middle region (when $X_{C}^{L}<X<X_{C}^{H}$ ) demonstrates that higher project return volatility lowers Supplier 1's optimal investment trigger. In this region, Supplier 1 changes its role from a follower to a leader and Supplier 2 alters its role from a leader to a follower when the project return volatility rises from 0.2 to 0.4 . Finally, the right region (when $X>X_{C}^{H}$ ) shows that the project return volatility first has a positive impact on Supplier 1's optimal investment trigger. In this region, Supplier 1 (2) again is always the leader (follower) when $\sigma=0.2$ and $\sigma=0.4$ due to the asymmetry between the two suppliers' investment costs.

When the investment project is liquidity constrained and when there is a rival supplier that can invest earlier to get the first-mover advantage, different from traditional literature, the change in the project return volatility can alter the roles of leader and follower when the risk of future funding shortfalls is taken into consideration. The increase in project return volatility can make the supplier's optimal investment trigger unchanged, higher, or even lower. Specifically, higher investment project return volatility can change the supplier's role from a follower to a leader, thereby lowering the supplier's optimal investment trigger.

\section{Conclusions}

When access to external financing is restricted, suppliers rely more on their internal funds to finance investment. Although this issue has long been recognized and analyzed in the literature, the interrelated effects of financing capacities and investment costs among suppliers have not yet previously been scrutinized with consideration of competition. In this paper we investigate the interdependent effects of asymmetric financing capacities and investment costs on optimal investment timing decisions in a duopoly with the first-mover advantage where the two suppliers' roles in the investment timing game are endogenously determined. 
Our model, complementing some existing literature, provides several new insights. First, in addition to asymmetric investment costs, we show that asymmetric financing capacities crucially impact the roles of leader and follower and optimal investment timing decisions. We demonstrate that facing a significant cost disadvantage the supplier with a higher financing capacity can still be the leader when the risk of future funding shortfalls is relatively high. Second, a weaker supplier that has a lower financing capacity and a small cost disadvantage can even be the leader under some degree of the risk of future funding shortfalls when its competitor prefers to defer investment. We further show that the weaker supplier that is still more liquidity constrained cannot be the leader anymore as its financing capacity improves and closes to that of the rival. Third, we show that only when the risk of future funding shortfalls is low, small asymmetry of investment costs leads to preemption. Finally, we demonstrate that the change in the investment project return volatility can alter the roles of leader and follower. An increase in project return volatility can make the supplier's optimal investment trigger unchanged, higher, or even lower. In particular, higher project return volatility can change the supplier's role from a follower to a leader, thereby lowering the supplier's optimal investment trigger.

\section{Acknowledgements}

We thank the reviewers for his/her thorough review and highly appreciate the comments and suggestions, which significantly contributed to improving the quality of the publication.

\section{Appendix A. The derivations of optimal investment triggers and value functions of the leader and follower when the two suppliers are liquidity unconstrained}

When the two unconstrained suppliers are in an asymmetric duopoly, the two suppliers' investment decisions are intertwined. By employing the standard backward argument of dynamic games, we first discuss the follower's investment decision.

Since the follower decides its optimal investment timing after the leader has invested, the follower's real option value $F_{i}^{u}(V)$ does not interact with the leader's decision, $i=1,2$, and is governed by the ordinary differential equation (ODE):

$$
\frac{1}{2} \sigma^{2} V^{2} \frac{\partial^{2} F_{i}^{u}}{\partial V^{2}}+(r-\delta) V \frac{\partial F_{i}^{u}}{\partial V}-r F_{i}^{u}=0 .
$$

The general solution is given by $F_{i}^{u}(V)=b_{1} V^{\beta}+b_{2} V^{\gamma}$, where $\beta_{1}>0>\beta_{2}$, and

$$
\beta(\gamma)=1 / 2+(r-\delta) / \sigma^{2}+(-) \sqrt{\left(2 r / \sigma^{2}\right)+\left(1 / 2+(r-\delta) / \sigma^{2}\right)^{2}} .
$$




\section{Manoj KUMAR}

The two unknowns $b_{1}$ and $b_{2}$ can be determined by the boundary conditions:

$\lim _{V \rightarrow 0} F_{i}^{u}(V)<0$ and $\lim _{V \rightarrow \hat{V}_{i, F}^{u}} F_{i}^{u}(V)=\left(1+q_{F}\right) \hat{V}_{i, F}^{u}-I_{i}$.

The real options values of the follower after the leader has invested are then given by:

$$
F_{i}^{u}(V)=\left(\left(1+q_{F}\right) \hat{V}_{i, F}^{u}-I_{i}\right)\left(\frac{V}{\hat{V}_{i, F}^{u}}\right)^{\beta}, \quad V \leq \hat{V}_{i, F}^{u} .
$$

According to the following smooth-pasting condition:

$$
\lim _{V \rightarrow \hat{V}_{i, F}^{u}} \frac{\partial F_{i}^{u}(V)}{\partial V}=1+q_{F}
$$

the follower's optimal investment decision is given by:

$$
\hat{V}_{i, F}^{u}=\frac{1}{1+q_{F}} \frac{\beta I_{i}}{\beta-1} .
$$

We observe that $\hat{V}_{i, F}^{u}>\hat{V}_{i, M}^{u}=\beta I_{i} /(\beta-1)$, i.e., the investment timing of the follower in a duopoly is later than that of an otherwise-identical supplier in a monopoly.

The investment value of the leader makes up two different forms: The leader invests immediately and the leader has not invested. Here, $L_{i}{ }^{u}(V)$ denotes the leader's value after its investment, which is a composite of two parts: pure investment value, $V$, and adjustment value due to the follower's investment. Because:

$\lim _{V \rightarrow 0} L_{i}^{u}(V)=0$ and $\lim _{V \rightarrow \hat{V}_{i, F}^{u}} L_{i}^{u}(V)=\left(1+q_{L}\right) \hat{V}_{i, F}^{u}$,

the leader's investment value when the leader has invested is:

$$
L_{i}^{u}(V)=V+q_{L} \hat{V}_{i, F}^{u}\left(\frac{V}{\hat{V}_{i, F}^{u}}\right)^{\beta}, \quad \hat{V}_{i, L}^{u} \leq V \leq \hat{V}_{i, F}^{u} .
$$

The leader's option to invest when the leader has not invested, $L_{i}^{u}(V)$, is governed by a similar-type ODE:

$\frac{1}{2} \sigma^{2} V^{2} \frac{\partial^{2} L_{i}^{u}}{\partial V^{2}}+(r-\delta) V \frac{\partial L_{i}^{u}}{\partial V}-r L_{i}^{u}=0$

The general solution is then given by: 
Asymmetric Suppliers' Optimal Investment Timing Decisions

$L_{i}^{u}(V)=d_{1} V^{\beta}+d_{2} V^{\gamma}, \quad V \leq \hat{V}_{i, L}^{u}$.

The two unknowns $d_{1}$ and $d_{2}$ can be determined by the non-bubble and valuematching boundary conditions:

$\lim _{V \rightarrow 0} L_{i}^{u}(V)>0$ and $\lim _{V \rightarrow \hat{V}_{i, L}^{u}} L_{i}^{u}(V)=L_{i}^{u}\left(\hat{V}_{i, L}^{u}\right)-I_{i}$

As a result, the value of the option to invest for the leader is:

$$
L_{i}^{u}(V)=\left(\hat{V}_{i, L}^{u}-I_{i}+q_{L} \hat{V}_{i, F}^{u}\left(\frac{\hat{V}_{i, L}^{u}}{\hat{V}_{i, F}^{u}}\right)^{\beta}\right)\left(\frac{V}{\hat{V}_{i, L}^{u}}\right)^{\beta}, \quad V \leq \hat{V}_{i, L}^{u} .
$$

In view of Equation (A.11), the adjustment value of the follower's investment, $q_{L} \hat{V}_{i, F}^{u}\left(\hat{V}_{i, L}^{u} / \hat{V}_{i, F}^{u}\right)^{\beta}$, is negative, demonstrating that the investment by the follower lowers the leader's value of the option to invest. Similarly, the optimal investment timing of pre-determined leader Supplier $i$ can be derived by the following smooth-pasting condition:

$$
\lim _{V \uparrow V_{i, L}^{u}} \frac{\partial \boldsymbol{L}_{i}^{u}(V)}{\partial V}=\lim _{V \downarrow V_{i, L}^{u}} \frac{\partial \boldsymbol{L}_{i}{ }^{u}(V)}{\partial V} .
$$

It can be shown that $\hat{V}_{i, L}^{u}=\hat{V}_{i, M}^{u}$. After considering the follower's optimal investment decision, the leader's optimal investment timing is still irrelevant to it. This result may seem counter-intuitive at first glance, but as noted by Pawlina and Kort (2006), the effects of the follower's investment decision on $L_{i}^{u}(V)$ and $L_{i}^{u}(V)$ are opposite and exactly offset each other. The simultaneous-investment equilibrium, often referred to as tacit collusion, is only possible if the two suppliers already compete within an industry and face the risk of cannibalizing their profits from existing assets (Pawlina and Kort, 2006). In our model, the threat of losing existing profits does not exist, and tacit collusion is therefore not sustainable.

To simplify the discussion, we also assume that the initial state of the project value is strictly less than the leader's optimal investment trigger, and mainly focus on analyzing the investment timing of a preemption game in which the possibility of simultaneous investment is excluded.

There is a persistent first-mover advantage in our model, and thus both suppliers have an incentive to become the leader. Moreover, low-cost Supplier 1 is more capable of preempting to be the leader than high-cost Supplier 2 is. In order to explain this more thoroughly, we first define $\xi_{i}^{u}(V)=\left(\boldsymbol{L}_{i}^{u}(V)-\boldsymbol{I}_{i}\right)-\boldsymbol{F}_{i}^{u}(V)$ as Supplier $i$ 's value difference between immediate investment being the leader and 
deferral of investment being the follower. Define $\hat{V}_{i, P}^{u}=\inf \left(V \geq 0: \xi_{i}^{u}(V)=0\right)$ as the smaller solution to $\xi_{i}^{u}(V)$, showing the earliest investment timing in which Supplier $i$ still has an incentive to preempt as the leader. Here, $\hat{V}_{i, P}^{u}$ is the smaller solution of the equation: $F_{i}^{u}\left(\hat{V}_{i, P}^{u}\right)=L_{i}^{u}\left(\hat{V}_{i, P}^{u}\right)-I_{i}, i=1,2$.

The leader-follower sequential equilibrium prevails all the time when the two suppliers are unconstrained, and low-cost Supplier 1 is always the leader adopting the investment decision of $\min \left(\hat{V}_{1, L}^{u}, \hat{V}_{2, P}^{u}\right)$, while high-cost Supplier 2 is the follower choosing $\hat{V}_{2, F}^{u}$. Similar to Carlson et al. (2014), when $\hat{V}_{1, L}^{u} \leq \hat{V}_{2, P}^{u}$ the optimal investment decision of Supplier 1 is not affected by any possible preemptive threat from Supplier 2. We define this case as the non-preemptive leader-follower equilibrium. When $\hat{V}_{1, L}^{u}>\hat{V}_{2, P}^{u}$, the incentive for preemptive investment by Supplier 2 plays an important role in Supplier 1's investment policy. In this case, $\hat{V}_{2, P}^{u}$ is adopted by Supplier 1 in order to maintain its role as the leader, which is called the preemptive leader-follower equilibrium. Notice that Pawlina and Kort (2006) define the preemptive equilibrium when $\hat{V}_{2, P}^{u}$ exists and define the sequential equilibrium if $\hat{V}_{2, P}^{u}$ does not exist.

\section{Appendix B. Numerical solution procedures for Equations (4), (8), (12) and (16)}

The PDEs employed in this paper have the same form and we discretize them by the Crank-Nicolson finite difference method. Let $H(X, V)$ be the value function satisfying the same form of PDE, which can be on a grid with nodes $\left\{\left(X_{n}, V_{m}\right): n=1, \ldots, N, m=1, \ldots, M\right\} \quad$, where $\quad X_{n}-X_{n-1}=d X \quad$ and $V_{m}=m d V$. At node $\left(X_{n}, V_{m}\right)$, for $2 \leq n \leq N$ and $2 \leq m \leq M$ the corresponding difference equation is:

$$
\begin{aligned}
0= & f_{1 m} H_{n, m-1}+f_{2 m} H_{n, m}+f_{3 m} H_{n, m+1}+f_{4 n} H_{n-1, m}+f_{5 n} H_{n+1, m} \\
& +f_{6 m}\left(H_{n+1, m+1}+H_{n-1, m-1}-H_{n+1, m-1}-H_{n-1, m+1}\right),
\end{aligned}
$$

$$
\begin{array}{cc}
\text { where } \quad f_{1 m}=\frac{\sigma^{2} V_{m}^{2}}{2 d V^{2}}-\frac{(r-\delta) V_{m}}{2 d V}, & f_{2 m}=r-\frac{\phi^{2}}{d X^{2}}-\frac{\sigma^{2} V_{m}^{2}}{d V^{2}} \\
f_{3 m}=\frac{\sigma^{2} V_{m}^{2}}{2 d V^{2}}+\frac{(r-\delta) V_{m}}{2 d V} \quad, \quad f_{4 n}=\frac{\phi^{2}}{2 d X^{2}}-\frac{r\left(X_{n}+G\right)}{2 d X}
\end{array}
$$


$f_{5 n}=\frac{\phi^{2}}{2 d X^{2}}+\frac{r\left(X_{n}+G\right)}{2 d X}, f_{6 m}=\frac{\rho \phi \sigma V_{m}}{4 d X d V}$, and $H_{n, m}=H\left(X_{n}, V_{m}\right)$. To solve the value function, we need to employ four boundary conditions to fit the edges of the grid, which vary for different value functions.

If the value function is $H(X, V)=M_{1}^{c}(X, V)$, then the four conditions are: (i) When $m=1$, we use $M_{1}^{c}\left(X_{n}, V_{0}\right)=0$, since $M_{1}^{c}\left(X_{n}, 0\right)=0$; (ii) When $m=M$, we then employ the free upper boundary $M_{1}^{c}\left(X_{n}, V_{M+1}\right)=$ $2 M_{1}^{c}\left(X_{n}, V_{M}\right)-M_{1}^{c}\left(X_{n}, V_{M-1}\right)$; (iii) When $n=1$, we suppose the liquidation constraint is binding, so that $M_{1}^{c}\left(X_{0}, V_{m}\right)=M_{1}^{u}\left(\alpha_{1} V_{m}\right)$; (iv) When $n=N$, we employ $M_{1}^{c}\left(X_{N+1}, V_{m}\right)=M_{1}^{u}\left(V_{m}\right)$ (unconstrained firms). With adequate start values, we solve the difference equation by iteratively replacing the calculated $M_{1}^{c}\left(X_{n}, V_{m}\right)$ with $M_{1}^{u}\left(\gamma V_{m}\right)$ if $X_{n}+G+M_{1}^{u}\left(\alpha_{1} V_{m}\right)<0$, and with $V_{m}-I_{1}$ at any node for which $X_{n}+G+\alpha_{1} V_{m} \geq I_{1}$ and $M_{1}^{c}\left(X_{n}, V_{m}\right)<V_{m}-I_{1}$. The stopping rule of iteration is when the largest chance in $M_{1}^{c}\left(X_{n}, V_{m}\right)$ is less than $I_{1} / 10000$. We thus numerically derive $\hat{V}_{1, M}^{c}(X)$ and $M_{1}^{c}(X, V)$.

If the value functions are $H(X, V)=F_{i}^{c}(X, V), i=1,2$, then the four conditions are: (i) When $m=1$, we use $F_{i}^{c}\left(X_{n}, V_{0}\right)=0$, since $F_{i}^{c}(X, 0)=0$; (ii) When $m=M$, we then employ the free upper boundary $F_{i}^{c}\left(X_{n}, V_{M+1}\right)=2 F_{i}^{c}\left(X_{n}, V_{M}\right)-F_{i}^{c}\left(X_{n}, V_{M-1}\right)$; (iii) When $n=1$, we suppose the liquidation constraint is binding, so that $F_{i}^{c}\left(X_{0}, V_{m}\right)=F_{i}^{u}\left(\alpha_{i}\left(1+q_{F}\right) V_{m}\right)$; (iv) When $n=N$, we employ $F_{i}^{c}\left(X_{N+1}, V_{m}\right)=F_{i}^{u}\left(V_{m}\right)$. With adequate start values, we solve the difference equation by iteratively replacing the calculated $F_{i}^{c}\left(X_{n}, V_{m}\right)$ with $F_{i}^{u}\left(\alpha_{i}\left(1+q_{F}\right) V_{m}\right) \quad$ if $\quad X_{n}+G+F_{i}^{u}\left(\alpha_{i}\left(1+q_{F}\right) V_{m}\right)<0 \quad$, and with $\left(1+q_{F}\right) V_{m}-I_{i}$ at any node for which $X_{n}+G+\alpha_{i}\left(1+q_{F}\right) V_{m} \geq I_{i}$ and $F_{i}^{c}\left(X_{n}, V_{m}\right)<\left(1+q_{F}\right) V_{m}-I_{i}$. The stopping rule of iteration is when the largest chance in $F_{i}^{c}\left(X_{n}, V_{m}\right)$ is less than $I_{i} / 10000$. We thus numerically derive $\hat{V}_{i, F}^{c}(X)$ and $F_{i}^{c}(X, V)$.

If the value functions are $H(X, V)=L_{i}^{c}(X, V), i=1,2$, then the four conditions are: (i) When $m=1$, we use $L_{i}^{c}\left(X_{n}, V_{0}\right)=0$, since $L_{i}^{c}(X, 0)=0$; 


\section{Manoj KUMAR}

(ii) When $m=M$, we assume the follower has invested and thus we employ the upper boundary $L_{i}^{c}\left(X_{n}, V_{m}\right)=\left(1+q_{L}\right) V_{m}$ for all $(n, m)$ where $V_{m} \geq \hat{V}_{j, F}^{c}\left(X_{n}\right)$; (iii) When $n=1$, we suppose the liquidation constraint is binding, so that $L_{i}^{c}\left(X_{0}, V_{m}\right)=\alpha_{i}\left(1+q_{L}\right) V_{m}$; (iv) When $n=N$, we employ $L_{i}^{c}\left(X_{N+1}, V_{m}\right)=L_{i}^{u}\left(V_{m}\right)$. With adequate start values, we solve the difference equation by iteratively replacing the calculated $L_{i}^{c}\left(X_{n}, V_{m}\right)$ with $\alpha_{i}\left(1+q_{L}\right) V_{m}$ if $X_{n}+G+\alpha_{i}\left(1+q_{L}\right) V_{m}<0$ given the four boundary conditions. The stopping rule of iteration is when the largest chance in $L_{i}^{c}\left(X_{n}, V_{m}\right)$ is less than $I_{i} / 10000$ . We can therefore obtain $L_{i}^{c}(X, V)$ and the value of immediate investment is $L_{i}^{c}(X, V)-I_{i}$.

If the value functions are $H(X, V)=L_{i}^{c}(X, V), i=1,2$, then the four conditions are: (i) When $m=1$, we use $L_{i}^{c}\left(X_{n}, V_{0}\right)=0$, since $L_{i}^{c}(X, 0)=0$; (ii) When $m=M$, we assume the follower has invested and we employ upper boundary $L_{i}^{c}\left(X_{n}, V_{M+1}\right)=L_{i}^{c}\left(X_{n}, V_{M+1}\right)-I_{i}$; (iii) When $n=1$, we suppose the liquidation constraint is binding, so that $L_{i}^{c}\left(X_{0}, V_{m}\right)=L_{i}^{u}\left(\alpha_{i}\left(1+q_{L}\right) V_{m}\right)$; (iv) When $n=N$, we employ $L_{i}^{c}\left(X_{N+1}, V_{m}\right)=L_{i}^{u}\left(V_{m}\right)$. With adequate start values, we solve the difference equation by iteratively replacing the calculated $L_{i}^{c}\left(X_{n}, V_{m}\right)$ with $L_{i}^{u}\left(\alpha_{i}\left(1+q_{L}\right) V_{m}\right)$ if $X_{n}+G+L_{i}^{u}\left(\alpha_{i}\left(1+q_{L}\right) V_{m}\right)<0$, and with $L_{i}^{c}\left(X_{n}, V_{m}\right)-I_{i}$ at any node for which $X_{n}+G+\alpha_{i}\left(1+q_{L}\right) V_{m} \geq I_{i}$ and $L_{i}^{c}\left(X_{n}, V_{m}\right)<L_{i}^{c}\left(X_{n}, V_{m}\right)-I_{i}$. The stopping rule of iteration is when the largest chance in $L_{i}^{c}\left(X_{n}, V_{m}\right)$ is less than $I_{i} / 10000$. We thus numerically derive $\hat{V}_{i, L}^{c}(X)$ and $L_{i}^{c}(X, V)$.

Finally, we can calculate $\hat{V}_{i, P}^{c m}(X)$ by the following two steps: (i) we define $\hat{V}_{i, P}^{c}\left(X_{n}\right)=\min \left\{V_{m}, 1 \leq m \leq M: L_{i}^{c}\left(X_{n}, V_{m}\right)-I_{i}=F_{i}^{c}\left(X_{n}, V_{m}\right)\right\}$, for all $n=1,2, \ldots, N$; and (ii) we then define $\hat{V}_{i, P}^{c m}\left(X_{n}\right)=\max \left(\hat{V}_{i, P}^{c}\left(X_{n}\right), \hat{V}_{i, L}^{c m}\left(X_{n}\right)\right)$, where $\hat{V}_{i, L}^{c m}\left(X_{n}\right) \equiv\left(I_{i}-G-X_{n}\right) / \alpha_{i}\left(1+q_{L}\right)$, for all $n=1,2, \ldots, N$. 


\section{References}

Aguerrevere, F.L. (2009). Real options, product market competition, and asset returns. Journal of Finance, 64(1), 957-983. https://doi.org/10.1111/i.1540-6261.2009.01454.x

Akdoğu, E., MacKay, P. (2008). Investment and competition. Journal of Financial and Quantitative Analysis, 43(1), 299-330. https://doi.org/10.1017/S0022109000003537;

Akdoğu, E., MacKay, P. (2012). Product market and corporate investment: Theory and evidence. Journal of Banking and Finance, 36(1), 439-453. https://doi.org/10.1016/i.jbankfin.2011.08.001

Almeida, H., \& Campello, M. (2007). Liquidity constraints, asset tangibility, and corporate Investment. Review of Financial Studies, 20(1), 1429-1460. https://doi.org/10.1093/rfs/hhm019.

Boyle, G.W. \& Guthrie, G.A. (2003). Investment, uncertainty, and liquidity. Journal of Finance, 58(1), 2143-2166. https://doi.org/10.1111/1540-6261.00600

Carlson, M., Dockner, E.J., Fisher, A., \& Giammarino, R. (2014). Leaders, followers, and risk dynamics in industry equilibrium. Journal of Financial and Quantitative Analysis, 49(1), 321349. http://doi.org/10.1016/ssrn.com/abstract $=891689$

Cleary, S., Povel, P., Raith, M. (2007). The U-shaped investment curve: Theory and evidence. Journal of Financial and Quantitative Analysis, 42(1), 1-39. https://doi.org/10.1017/S0022109000002179

Denis, D.J. \& Sibilkov, V. (2010). Financial constraints, investment, and the value of cash holdings. Review of Financial Studies, 23(1), 247-269. https://doi:10.1093/rfs/hhp031

Dixit, A.K. \& Pindyck, R.S. (1994). Investment under Uncertainty. Princeton University Press, New Jersey.

Fresard, L. (2010). Financial strength and product market behavior: The real effects on corporate cash holdings. Journal of Finance, 65(1), 1097-1122. https://doi.org/10.1111/j.1540-6261.2010.01562.x

Fudenberg, D. \& Tirole, J. (1985). Pre-emption and rent equalization in the adoption of new technology. Review of Economic Studies, 52(1), 383-401. http://doi: 10.2307/2297399.

Grenadier, S.R. (2002). Option exercise games: An application to the equilibrium investment strategies of firms. Reviews of Financial Studies, 15(1), 691-721. http://www4.oup.co.uk/revfin/subinfo/

Haushalter, D., Klasa, S. \& Maxwell, W.F. (2008). The influence of product market dynamics on a firm's cash holdings and hedging behavior. Journal of Financial Economics, 84(1), 797 825. https://doi.org/10.1016/i.jfineco.2006.05.007

Jou, J.B. \& Lee, T. (2008). Irreversible investment, financing, and bankruptcy decisions in an oligopoly. Journal of Financial and Quantitative Analysis, 43(1), 769-786. https://doi.org/10.1016/j.idorg.2008.04.001

Kumar, M., Raman, J. \& Raman, P. (2015). Suppliers Dynamic Approach to Invest in R\&D with Sunk Costs in Indian Contexts. Eurasian Journal of Business and Economics, 8 (15), 6193. https://doi: 10.17015/ejbe.2015.015.04

Lyandres, E. (2007). Costly external financing, investment timing, and investment-cash flow sensitivity. Journal of Corporate Finance, 13(1), 959-980. https://doi:10.1016/i.jcorpfin.2007.07.001 


\section{Manoj KUMAR}

Lyandres, E., \& Palazzo, B. (2016). Cash holdings, competition, and innovation. Journal of Financial and Quantitative Analysis, 51(6), 1823-1861. https://doi.org/10.1017/S0022109016000697

Majd, S. \& Pindyck, R.S. (1987). Time to build, option value, and investment decisions. Journal of Financial Economics, 18(1), 7-27. https://doi:10.1016/0304-405X(87)90059-6.

Mason, R., Weeds, H. (2010). Investment, uncertainty and pre-emption. International $\begin{array}{llll}\text { Journal of Industrial Organization, 28(1), 278-297. } & \text { 28 }\end{array}$ https://doi.org/10.1016/j.ijindorg.2009.09.004

McDonald, R., Siegel, D. (1986). The value of waiting to invest. Quarterly Journal of Economics, 101(1), 707-728. https://doi.org/10.2307/1884175

Munos, B. (2009). Lessons from 60 years of pharmaceutical innovation. Nature Reviews Drug Discovery, 8(1), 959-968. https://doi:10.1038/nrd2961 ... AnAlySiS.

Pawlina, G., Kort, P.M. (2006). Real options in an asymmetric duopoly: Who benefits from your competitive disadvantage? Journal of Economics and Management Strategy, 15(1), 135. https://doi.org/10.1111/j.1530-9134.2006.00090.x ...

Schroth, E. \& Szalay, E. (2010). Cash breeds success: The role of financing constraints in patent races. Review of Finance, 14(1), 73-118. https://doi.org/10.1093/rof/rfp020 